\title{
PSYCHO-SOCIAL CORRELATES AND PREDICTORS OF QUALITY OF LIFE AMONG VICTIMS OF DOMESTIC VIOLENCE
}

\author{
SUJATHA KOSHY, DR. PRATIMA KAUSHIK
}

\begin{abstract}
:
Domestic violence is very common problem in individuals, especially females in Indian scenario, is often associated with severe mental illness; yet there is very little research in this setting. The present study aimed to investigate the relationship psychological distress, social support and quality of life among victims of domestic violence. For this purpose, various NGO's in Delhi and NCR who support victims of domestic violence were approached. The subjects included 100 married women (22-45 years of age) who were victims of domestic violence. SSQ (Sarason, I.G., Levine, H.M., Basham, R.B., et al. (1983), DAS-21 (Marianna Szabo, 2010), and WHOQOL-BREF (WHO, 1996) were employed. Correlation coefficient and regression analysis was done. The findings suggested that both psychological and psychosocial factors such as depression, anxiety, stress, social appraisal, belongingness and tangibility can have a significant impact on quality of life of victims of domestic violence.
\end{abstract}

\section{Keywords:}

domestic violence, psychological distress, social support, quality of life, belongingness

JEL Classification: 131

\section{Authors:}

SUJATHA KOSHY, AIPS, Amity University, India, Email: pratima.pandey@yahoo.co.in DR. PRATIMA KAUSHIK, AIPS, Amity University Uttar Pradesh, Noida-125, India, Email: pratima.pandey@yahoo.co.in

\section{Citation:}

SUJATHA KOSHY, DR. PRATIMA KAUSHIK (2017). Psycho-social Correlates and predictors of Quality of Life Among Victims of Domestic Violence. International Journal of Social Sciences, Vol. VI(1), pp. 41-52., 10.20472/SS.2017.6.1.004 


\section{Introduction}

Domestic Violence against women is a serious problem concerning human rights violation. In last two decades violence against women has emerged as the most burning issue throughout the globe Domestic violence (also domestic abuse, spousal abuse, intimate partner violence, battering, or family violence) is a pattern of behaviour which involves violence or other abuse by one person against another in a domestic setting, such as in marriage or cohabitation.

A 2014 study in The Lancet reports that the reported sexual violence rate in India is among the lowest in the world, the large population of India means that the violence affects 27.5 million over women their lifetime (Samarasekera \& Horton, 2015). Overwhelmingly domestic violence is experienced by women and the perpetrator is male. Yet although in the vast majority of cases it is male to female, we should recognize that men, children and the elderly can be abused, and that domestic violence also occurs in gay and lesbian relationships.

Domestic Violence against women is a serious problem concerning human rights violation. In last two decades' violence against women has emerged as the most burning issue throughout the globe. Domestic violence (also domestic abuse, spousal abuse, intimate partner violence, battering, or family violence) is a pattern of behaviour which involves violence or other abuse by one person against another in a domestic setting, such as in marriage or cohabitation. According to a National family and health survey in 2005 , total lifetime prevalence of domestic violence was $33.5 \%$ and $8.5 \%$ for sexual violence among women aged 15-49. A 2014 study in the Lancet reports that the reported sexual violence rate in India is among the lowest in the world, the large population of India means that the violence affects 27.5 million over women their lifetime (Wagman et al. 2015).

\subsection{Psycho-social correlates of Domestic Violence}

It has various effects on the mind, body and spirit. It is natural to experience these, and acknowledging the effects can be an important first step in embarking on a process towards restoration and healing. People who are exposed to domestic violence often experience physical, mental or spiritual shifts that can endure and worsen if they are not addressed. Increased anxiety, post-traumatic stress disorder, anxiety symptoms and depression symptoms are commonly observed among survivors of domestic violence (Smith, Fowler \& Niolon, 2014). Anxiety affects around $16 \%$ of the population at any one time. However this percentage is significantly increased in those who are suffering, or who have survived domestic abuse. Depression remains the most common symptom exhibited by survivors of domestic violence (Astin et al. 1993; Hasanovic et al. 2005). 
Social support is the perception and actuality that one is cared for, has assistance available from other people, and that one is part of a supportive social network. If the victim does not get the required feeling of belongingness, love, appraisal and tangible support the individual suffer from psychological problems like stress, depression, anxiety etc. Social support, whether from a trusted group or valued individual, has been shown to reduce the psychological and physiological consequences of stress, and may enhance immune function. Numerous studies indicate social support is essential for maintaining physical and psychological health. The harmful consequences of poor social support and the protective effects of good social support in mental illness have been well documented. Social support may moderate genetic and environmental vulnerabilities and confer resilience to stress, possibly via its effects on the hypothalamic-pituitary-adrenocortical (HPA) system, the noradrenergic system, and

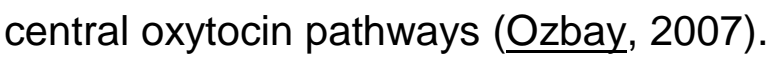

Quality of life is a highly subjective measure of happiness that is an important component of many financial decisions. Low level of quality of life among victims of domestic violence is mostly due to psychological and psychosocial problems. Factors that also play a role in quality of life varies according to personal preferences are financial security, job satisfaction, family life, health and safety (Kumar, Nehra \& Dahiya, 2013).

Increased health problems such as injury, chronic pain, gastrointestinal, and gynaecological signs including sexually-transmitted diseases, depression, and posttraumatic stress disorder are well documented by several studies in abused women in various settings. Intimate partner violence has been noted in $3-13 \%$ of pregnancies in many studies from around the world, and is associated with detrimental outcomes to mothers and infants (Campbell \& Lancet, 2016). Analysis of risk factors of domestic violence highlights the pivotal roles of the male partner's alcohol consumption and his perceived human immunodeficiency virus (HIV) risk in increasing the risk of male against female domestic violence (Koenig \& Lutalo, 2003).

Family violence and domestic abuse have a significant impact on the quality of life of women's and children on the long-terms bases. A recent study in the Journal of the American Medical Association found that women, who reported experiencing domestic abuse, had an associated higher lifetime prevalence of mental health disorders, dysfunction and disability. The study pointed to the sad fact that violence against women is a major public health concern, contributing to high levels of illness and death worldwide (Taft, 2013).

Domestic spousal violence against women has far-reaching mental health implications. Logistic regression showed that women reporting 'any violence' - 'slap', 'hit', 'kick' or 'beat' (OR 2.2, 95\% Cl 2.0-2.5) - or 'all violence' - all of the four types of physically 
violent behaviour (OR 3.5, 95\% Cl 2.94-3.51) - were at increased risk of poor mental health. This indicates a strong association between domestic spousal violence and poor mental health, and underscore the need for appropriate interventions (Kumar, Suresh \& Jeyaseelan , 2005).

Campbell, Spackman \& Sullivan (2010) investigated an intervention designed to increase battered women's social support and make their existing supports more responsive to their dire needs. Key findings substantiate the strong relationship between social support and psychological well-being of battered women.

A recent comprehensive review published by the World Health Organization in 2013 reported that 'the global prevalence of physical and/or sexual intimate partner violence among all ever-partnered women was $30 \%$. The prevalence was highest in the WHO African, Eastern Mediterranean and South-East Asia Regions, where approximately $37 \%$ of ever-partnered women reported having experienced physical and/or sexual intimate partner violence at some point in their lives' (a total of 185 studies from 86 countries included and data from 155 studies in 81 countries provided the estimates). The review reported the following health effects of intimate partner violence: HIV and other sexually transmitted infections, induced abortion, low birth weight and prematurity, harmful alcohol use, depression and suicide, non-fatal injuries, and fatal injuries (Tavoli \& Amirpour et al., 2016).

The present study looks at the various factors such as psychological and psychosocial distress that affects the quality of life among victims of domestic violence. It is necessary to understand psychological and social effects of domestic violence such as Anxiety, Stress, Depression, disassociation and many more. These traumas can have various effects on the mind, body and spirit. It is natural to experience these, and acknowledging the effects can be an important first step in embarking on a process towards restoration and healing. People who are exposed to domestic violence often experience physical, mental or spiritual shifts that can endure and worsen if they are not addressed and thus the same can be mitigated by family support, professional counselling, laws and medical help. The main aim of the study was to assess impact of psycho-social factors such as Psychological Distress (including depression, anxiety and stress) and Social Support on Quality of Life among victims of domestic violence in Indian women.

\section{Method}

\subsection{Participants}

The present study aimed to examine the impact of psycho-social factors such as Psychological Distress (including depression, anxiety and stress) and Social Support on Quality of Life among victims of domestic violence in Indian women. 
A sample of 100 married women who experienced domestic violence, of age 22-45 years were selected from various NGO's located in Delhi and NCR.

Following hypotheses were formulated:

$\mathrm{H}_{1}$ : There will be a significant relationship among psychological distress, social support and quality of life among victims of Domestic Violence.

$\mathrm{H}_{2}$ : Low psychological distress and high Social Support will significantly predict better quality of life among victims of Domestic Violence.

\subsection{Measures}

Social Support Questionnaire (Sarason, et al. (1983): The scale is a Likert type rating scale with a 40-items made up of four subscales which are tangible support, belonging support, self-esteem support and appraisal support. The Subscales helps in examining in an investigation of to what level tangible, belongingness and appraisal support is being received along with the level of self-esteem the subject has to overcome the stressful event. Its reliability and validity was .772 to .873 ; 289 to .578 at 0.5 level or above.

WHO Quality of Life-BREF (WHOQOL-BREF, 1996): World Health Organization Quality of Life (WHOQOL)-BREF (WHOQOL-BREF, 1996) is a 5 point Likert type rating scale with 26 items. The scale domains in the current study were physical health, psychological wellbeing, social relationships and environmental health. The test-retest reliability varied from 0.66 to 0.87 and internal consistency reliability varied from 0.66 to 0.84 for all 4 domains.

Depression, Anxiety and Stress Scale (Marianna Szabo, 2010) (DASS 21): The DASS 21 is a 21 item self-report questionnaire designed to measure the severity of a range of symptoms common to both Depression and Anxiety. In completing the DASS, the individual is required to indicate the presence of a symptom over the previous week. Each item is scored from 0 (did not apply to me at all over the last week) to 3 (applied to me very much or most of the time over the past week). Its reliability and validity was .667 to $770 ; .489$ to .678 at 0.5 level or above.

\subsection{Procedure}

For the data collection various Non-Governmental Organisations who support victims of domestic violence were approached and with each participant a comfortable rapport was established. The participants were informed about the study and consent was taken and participants were ensured about the confidentiality. The questionnaires were administered individually. Scoring of each scale was done and scores were entered into excel sheet manually. Pearson's correlation coefficient and regression analysis were calculated to check the hypotheses. 


\section{Results}

The results were computed using SPSS 19.0 version. The data was screened to check the minimum and maximum values for all scales.

\subsection{Correlating variables}

Table 1 Inter-correlation Matrix showing the relationship between Psychological distress, Quality of life and Social Support.

\begin{tabular}{|c|c|c|c|c|c|c|c|c|c|c|}
\hline & (1) & (2) & (3) & (4) & (5) & (6) & (7) & (8) & (9) & (10) \\
\hline DEP (I) & 1 & & & & & & & & & \\
\hline ANX (2) & $.905^{\star \star}$ & 1 & & & & & & & & \\
\hline STRS (3) & $.918^{\star *}$ & $.958^{\star *}$ & 1 & & & & & & & \\
\hline QOL1 (4) & $-.821^{* *}$ & $-.815^{\star \star}$ & $-.856^{\star *}$ & 1 & & & & & & \\
\hline QOL2 (5) & $-.902^{* *}$ & $-.925^{\star *}$ & $-.931^{\star *}$ & $.916^{\star}$ & 1 & & & & & \\
\hline QOL3 (6) & $-.754^{* *}$ & $-.722^{* *}$ & $-.765^{\star *}$ & $.766^{*}$ & $.778^{*}$ & 1 & & & & \\
\hline QOL4 (7) & $-.867^{* *}$ & $-.879^{* *}$ & $-.880^{\star *}$ & $.845^{\star}$ & $.922^{*}$ & $.702^{* *}$ & 1 & & & \\
\hline SS1 (8) & $-.800^{* *}$ & $-.832^{* *}$ & $-.865^{\star *}$ & $.775^{*}$ & $.803^{*}$ & $.679^{* *}$ & $.791^{*}$ & 1 & & \\
\hline SS2 (9) & $-.789^{* *}$ & $-.800^{\star *}$ & $-.819^{* *}$ & $.794^{*}$ & $.838^{*}$ & $.728^{\star *}$ & $.797^{*}$ & $.736^{*}$ & 1 & - \\
\hline SS3 (10) & $-.802^{* *}$ & $-.760^{* *}$ & $-.790^{* *}$ & $.736^{*}$ & $.774^{*}$ & $.624^{\star \star}$ & $.740^{*}$ & $.766^{\star}$ &. & 1 \\
\hline
\end{tabular}

Note: DASS-21 dimensions: DEP- Depression, ANX-Anxiety, STRS- Stress, Quality of Life dimensions: QOL1- Physical Health, QOL2- Psychological Health, QOL3- Social Relationships, QOL4- Environment; Social Support dimensions: SS1- Social Appraisal, SS2- Belongingness, SS3- Tangible 
${ }^{* *}$ significant at 0.01 level

The above table shows Inter-Correlation Matrix showing the relationship between psychological distress, quality of life and social support and the results showed dimensions of Psychological Distress viz. depression was positively significantly correlated with anxiety $(0.9)$, stress $(0.91)$, negatively significantly correlated with physical health $(-0.82)$, psychological health $(-0.9)$, social relation $(-7.54)$, environment ($8.67)$, social appraisal $(-0.8)$, belongingness $(-0.7)$ and tangible $(-0.8)(p<0.01)$, which suggest that high level of depression in female victims of domestic violence had high level of anxiety, stress and low on quality of life dimensions and social support dimensions.

Anxiety was positively significantly correlated with stress (0.9), and negatively significantly correlated with Quality of Life dimensions, viz. physical health (-.81), psychological health (-.92), social relation (-.72), environment (-.87), and social support dimensions viz., social appraisal (-.83), belongingness $(-.80)$ and tangible $(-.76)$ $(p<0.01)$. This clearly states that anxiety increases stress and negatively contributes to quality of life and perception of social support.

Stress was negatively significantly correlated with quality of life dimensions viz., psychological health (-.93), social relation (-.76), environment (-.88), and social support dimensions viz., social appraisal (-.86), belongingness (-.81) and tangible (-.79) $(p<0.01)$. Suggesting that stress puts its negative effect on quality of life and perception of social support.

In Quality of Life domains viz., Physical health was significantly correlated with psychological health (.91), social relation (.76), environment (.84), social appraisal (.77), belongingness $(.79)$ and tangible $(.73)(p<0.01)$. Psychological health was significantly correlated with social relation (.77), environment (.92) social appraisal (.80), belongingness $(.83)$ and tangible $(.77)(p<0.01)$. Social relation was significantly correlated with environment (.702) social appraisal (.67), belongingness (.72) and tangible $(.62)(p<0.01)$. Environment was significantly correlated with social appraisal $(.79)$, belongingness $(.79)$ and tangible $(.74)(p<0.01)$. This suggests that healthy social support leads to healthy quality of life in victims of domestic violence.

The above correlation table states that psychological distress is negatively related with quality of life and is positively related with it. Psychological distress lowers quality of life and adequate social support uplifts the levels of quality of life.

The hypothesis 1 is accepted, which states that dimensions of psychological distress, social support and quality of life are significantly related. 


\subsection{Predicting Variables}

Table 2: Predictors of Quality of Life

\begin{tabular}{|c|c|c|c|c|c|c|}
\hline IV & DEP & ANX & STRS & SS1 & SS2 & SS3 \\
\hline DV & $\beta(t)$ & $\beta(t)$ & $\beta(t)$ & $\beta(t)$ & $\beta(t)$ & $\beta(t)$ \\
\hline QOL1 & $-0.17(1.29)$ & $0.17(0.95)$ & $-0.54(-2.56)^{*}$ & $0.98(0.94)$ & $0.25(2.78)^{*}$ & $0.29(0.3)$ \\
\hline QOL2 & $\begin{array}{l}-0.20 \\
(2.27)^{\star}\end{array}$ & $-0.30(-2.63)^{\star}$ & $-0.31(2.29)$ & $\begin{array}{l}-0.04(- \\
0.59)\end{array}$ & $0.19(3.17)^{\star \star}$ & $0.01(0.19)$ \\
\hline QOL3 & $\begin{array}{l}-0.36 \\
(2.12)^{\star}\end{array}$ & $0.30(1.37)$ & $-0.50(-1.9)$ & $0.07(0.55)$ & $0.32(2.79)^{\star}$ & $-0.12(-1.1)$ \\
\hline QOL4 & $\begin{array}{l}-0.28 \\
(2.34)^{\star}\end{array}$ & $-0.30(-1.92)$ & $-0.10(-0.5)$ & $0.09(1.01)$ & $0.18(2.23)$ & $\begin{array}{l}-0.01(- \\
0.18)\end{array}$ \\
\hline
\end{tabular}

Note: DASS-21 dimensions: DEP- Depression, ANX-Anxiety, STRS- Stress, Quality of Life dimensions: QOL1- Physical Health, QOL2- Psychological Health, QOL3- Social Relationships, QOL4- Environment; Social Support dimensions: SS1- Social Appraisal, SS2- Belongingness, SS3- Tangible

*significant at 0.05 level, ** significant at 0.01 level

Table 2 shows linear regression analysis to determine the predictors of quality of life dimensions by the victim of domestic violence on psychological distress (Depression, Anxiety and Stress) and Social support (Social appraisal, Belongingness and Tangible).

The results showed that physical health based on stress and belongingness. A significant regression equation was found $(F(6,93)=51.482, p<0.01)$, with an $R^{2} 0.69$ (stress); $54.854+(-3.378) ; 54.854+1.902$ (belongingness). Psychological health based on Depression, Anxiety, Stress and Belongingness. A significant regression equation was found $(F(6,93)=141.474, p<0.01)$, with an $R^{2}$ of 0.901 . Social relationship based on depression and belongingness. A significant regression equation was found $(F(6$, $93)=27.388, \quad \mathrm{p}<0.01)$, with an $\mathrm{R}^{2}$ of 0.639 . Environment based on depression, anxiety and belongingness. A significant regression equation was found $(F(6,93)=69.7866, p<0.01)$, with an $R^{2}$ of 0.818 .

The above regression table suggests the stress, anxiety and depression negatively significantly predicts all domains of quality of life. Psychological distress plays a significant role in lowering the level of quality of life in the victims of domestic violence. The scores of regression also states that 'belongingness', a dimension of social support, 
significantly positively predicts all the dimensions of quality of life. Hence, sense of belongingness helps in elevating quality of life in female victims of domestic violence.

\section{DISCUSSION}

The present study aimed to assess the psychological distress and quality of life among victims of domestic violence. The participants age ranged between 22 and 45 years, and total of 100 women were included from various Non-Government Organizations (NGO's) who provide support of victims of domestic violence in Delhi and NCR, India.

This study can help individuals across the world to understand serious impacts of domestic violence including physical, mental and emotional effects on an individual and quality of life. It becomes important for us to understand psychological and social effects of domestic violence such as anxiety, stress, depression, disassociation and many more as these traumas can have various effects on the mind, body and spirit (Black et al., 2011).

The findings of the study indicated that the dimensions of quality of life which are health, psychological health, social relationship and environment were significantly correlated with depression, anxiety, stress, social appraisal, belongingness and tangibility.

Linear regression analysis was calculated to assess the predictors of quality of life. It was found that physical health was significantly predicted by stress and belongingness at 69 per cent $(p<0.01)$, psychological health was significantly predicted by depression, anxiety, stress and belongingness at 90 per cent $(p<0.01)$, social relationship was significantly predicted by depression and belongingness at 63 per cent $(p<0.01)$ and environment a domain of quality of life was significantly predicted by depression, anxiety and belongingness at 81 per cent $(p<0.01)$.

Hegarty (2011) suggested that domestic violence is a common hidden problem for women attending clinical practice and is a major cause of mental ill health globally. Household misuse incorporates demonstrations of physical hostility, mental misuse, constrained intercourse and different types of sexual pressure, and different controlling practices, for instance detaching from family and companions, checking developments and hardship of fundamental necessities. Tavoli \& Amirpour, 2016 mentioned that personal satisfaction in pregnant ladies who experienced domestic violence, is a critical issue both for ladies' and baby's wellbeing.

Findings of the present study were supported by several studies. Hegarty, 2011 suggested that domestic violence is a common hidden problem for women attending clinical practice and is a major cause of mental ill health globally. Household misuse incorporates demonstrations of physical hostility, mental misuse, constrained intercourse and different types of sexual pressure, and different controlling practices, for instance detaching from family and companions, checking developments and hardship 
of fundamental necessities. This misuse is the main source of bleakness and mortality for ladies of childbearing age, with the fundamental commitment being from the psychological wellness results of misuse. Aggressive behaviour at home has likewise an intergenerational impact with kids seeing misuse having different wellbeing issues.

Tavoli \& Amirpour, (2016) mentioned that personal satisfaction in pregnant ladies who experienced domestic violence, is a critical issue both for ladies' and baby's wellbeing. This study planned to analyse personal satisfaction in a gathering of ladies who were presented to aggressive behaviour at home amid pregnancy. Carlos \& Esteves, (2014) investigated a research on Social support from the perspective of adolescent victims of domestic violence. It was presumed that the specified wellsprings of bolster should be upgraded and extended. With the present multifaceted nature of the bleakness and mortality profiles, particularly in kids and youths, the (re)signification and the (re)construction of wellbeing activities is basic.

\section{Conclusion}

The study aimed to study the psychological and psychosocial effects on quality of life among victims of domestic violence. The major finding was the significant factors such as psychological and psychosocial that influences their quality of life. From the results it was inferred that both psychological and psychosocial factors such as depression, anxiety, stress, social appraisal, belongingness and tangibility can have a significant impact on individual's quality of life.

\section{References}

Astin MC, Lawrence KJ, Foy DW. Posttraumatic stress disorder among battered women: risk and resiliency factors. Violence Vict. 1993;8:17-28.

Black, M.C., Basile, K.C., Breiding, M.J., Smith, S.G., Walters, M.L., Merrick, M.T., Chen, J., \& Stevens, M.R, The National Intimate Partner and Sexual Violence Survey (NISVS): 2010.

Campbell, J., \& Lancet. (2016, June Friday). Violence Against Women - General Physical and Mental Consequences. The Lancet. 359(9314) 1331-1336. https://doi.org/10.1016/S0140-6736(02)083368

Campbell, J.D., Spackman, D.E., Sullivan, S.D. (2010). The costs and consequences of omalizumab in uncontrolled asthma from a USA payer perspective. Allergy.;65(9):1141-8. https://doi.org/10.1111/j.1398-9995.2010.02336.x

Carlos, Diene Monique et al. Social support from the perspective of adolescent victims of domestic violence. Rev. esc. enferm. USP [online]. 2014, vol.48, n.4 [cited 2016-11-11], pp.610-617.

Hasanovic M, Sinanovic O, Pavlovic S. Acculturation and psychological problems of adolescents from Bosnia and Herzegovina during exile and repatriation. Croat Med J. 2005;46:105-15. 
Hegarty K. (2011). Domestic violence: the hidden epidemic associated with mental illness. The British Journal of Psychiatry.198 (3) 169-170. https://doi.org/10.1192/bjp.bp.110.083758

International Institute for Population Sciences (IIPS) and Macro International. 2007. National Family Health Survey (NFHS-3), 2005-06: India: Volume I. Mumbai: IIPS.

Koenig, M.A., Lutalo, T., Zhao, F., Nalugoda, F., Wabwire-Mangen, F., Kiwanuka, N., Wagman, J., Serwadda, D., Wawer, M., Gray, R. (2003). Domestic violence in rural Uganda: evidence from a community-based study. Bull World Health Organ. 2003;81(1):53-60.

Kumar, P., Nehra, D., \& Dhaiya, S. (2013). Women Empowerment and Mental Health: A Psychological Aspect. Delhi Psychiatry Journal. 16(1) 57-65.

Kumar, S., Jeyaseelan, L., \& Suresh, A. (2005). Domestic violence and its mental health correlates in Indian women. Br J Psychiatry. 187:62-7. https://doi.org/10.1192/bjp.187.1.62

Marianna Szabo (2010). The short version of the Depression Anxiety Stress Scales (DASS-21): Factor structure in a young adolescent sample. Journal of Adolescence. 33 (2010) 1-8. https://doi.org/10.1016/j.adolescence.2009.05.014

Marie NG, Tom Fleming, Margaret Robinson, Blake Thomson, Nicholas Graetz, Christopher Margono, Erin C Mullany, Stan Biryukov, Cristiana Abbafati et al. (2014). Global, regional, and national prevalence of overweight and obesity in children and adults during 1980-2013: a systematic analysis for the Global Burden of Disease Study 2013. The Lancet. 384(9945), 766-781. https://doi.org/10.1016/S0140-6736(14)60460-8

Ozbay, F., Johnson, D. C., Dimoulas, E., Morgan, C. A., Charney, D., \& Southwick, S. (2007). Social Support and Resilience to Stress: From Neurobiology to Clinical Practice. Psychiatry (Edgmont). 4(5), 35-40.

Samarasekera, U., Horton, R. (2015). Prevention of violence against women and girls: a new chapter. The Lancet. 385, 9977; p 1480-82. https://doi.org/10.1016/S0140-6736(14)61775-X

Sarason, I.G., Levine, H.M., Basham, R.B., et al. (1983). Assessing social support: The Social Support Questionnaire. Journal of Personality and Social Psychology, 44, 127- 139. https://doi.org/10.1037/0022-3514.44.1.127

Smith, S.,Fowler, K. \& Niolon, P. (2014) Intimate partner homicide and corollary victims in 16 states: National violent death reporting system,(2003-2009). American Journal of Public Health, 104(3), 461-466. https://doi.org/10.2105/AJPH.2013.301582

Sullivan, C., Campbell, R., Angelique, H., \& Davidson, A. (1994). An Advocacy Intervention Program for Women with Abusive Partners: American Journal of Community. Am J Community Psychol. 22(1):101-22. https://doi.org/10.1007/BF02506819 
Taft A, O'Doherty L, Hegarty K, Ramsay J, Davidson L, Feder G. Screening women for intimate partner violence in healthcare settings. Cochrane Database Syst Rev. 2013;4:CD007007. https://doi.org/10.1002/14651858.cd007007.pub2

Tavoli, Z., Tavoli, A., Amirpour, R., \& Hossein, R. (2016, January 26). Quality of life in women who were exposed to domestic violence during pregnancy. BMC Pregnancy Childbirth. 26; 16:19.

Tavoli, Z., Tavoli, A., Amirpour, R., Hosseini, R., Montazeri, A. (2016). Quality of life in women who were exposed to domestic violence during pregnancy. BMC Pregnancy Childbirth. 2016 Jan 26;16:19. https://doi.org/10.1186/s12884-016-0810-6

Wagman, J. A., Gray, R.H., Campbell, J.C., Thoma, M., Ndyanabo, A., Ssekasanvu, J., Nalugoda, F., Kagaayi, J., Nakigozi, G., Serwadda, D. \& Brahmbhatt, H. (2015). Effectiveness of an integrated intimate partner violence and HIV prevention intervention in Rakai, Uganda: analysis of an intervention in an existing cluster randomised cohort. Lancet Glob Health. 3(1): e23-e33. https://doi.org/10.1016/S2214-109X(14)70344-4

World Health Organization (1996). WHOQOL-BREF: Introduction, administration, scoring and generic version of the assessment, field trial version, December 1996. Geneva: World Health Organization. 